\title{
Does Obstructive Sleep Apnea Worsen During REM Sleep?
}

\section{PEREGRIM ${ }^{1}$, S. GREŠOVÁ ${ }^{1}$, M. PALLAYOVÁ ${ }^{1}$, B. L. FULTON ${ }^{2}$, J. ŠTIMMELOVÁ ${ }^{1}$, I. BAČOVÁ ${ }^{1}$, A. MIKUL'AKOVÁ ${ }^{3}$, Z. TOMORI ${ }^{1}$, V. DONIČ ${ }^{1}$}

${ }^{1}$ Department of Medical Physiology, Faculty of Medicine, P. J. Šafárik University, Košice, Slovakia, ${ }^{2}$ Health and Science Division, West Virginia Northern Community College, Wheeling, WV, USA, ${ }^{3}$ Department of Pathology, Faculty of Medicine, P. J. Šafárik University, Košice, Slovakia

Received August 29, 2012

Accepted June 28, 2013

On-line September 10, 2013

\section{Summary}

Although it is thought that obstructive sleep apnea (OSA) is worse during rapid eye movement (REM) sleep than in non-REM (NREM) sleep there are some uncertainties, especially about apnoe-hypopnoe-index (AHI). Several studies found no significant difference in AHI between both sleep stages. However, REM sleep is associated more with side sleeping compared to NREM sleep, which suggests that body position is a possible confounding factor. The main purpose of this study was to compare the AHI in REM and NREM sleep in both supine and lateral body position. A retrospective study was performed on 422 consecutive patients who underwent an overnight polysomnography. Women had higher AHI in REM sleep than NREM sleep in both supine (46.05 \pm 26.26 vs. $23.91 \pm 30.96$, $\mathrm{P}<0.01)$ and lateral $(18.16 \pm 27.68$ vs. $11.30 \pm 21.09, \mathrm{P}<0.01)$ body position. Men had higher AHI in REM sleep than NREM sleep in lateral body position $(28.94 \pm 28.44$ vs. $23.58 \pm 27.31, \mathrm{P}<0.01)$, however, they did not reach statistical significance in supine position $(49.12 \pm 32.03$ in REM sleep vs. $45.78 \pm 34.02$ in NREM sleep, $\mathrm{P}=0.50$ ). In conclusion, our data suggest that REM sleep is a contributing factor for OSA in women as well as in men, at least in lateral position.

\section{Key words}

Obstructive sleep apnea • Apnoe-hypopnoe-index • Body position - Mixed apnea

\section{Corresponding author}

I. Peregrim, Department of Medical Physiology, Faculty of Medicine, P. J. Šafárik University, Trieda SNP 1, Košice, Slovakia. Fax: 0042155 6423763. E-mail: igor.peregrim@upjs.sk

\section{Introduction}

Obstructive Sleep Apnea (OSA) is characterized by a presence of at least 5 obstructive apneas and/or hypopneas per hour (h) of sleep. During these events, respiratory muscles try to perform inspiration repeatedly but fail because of upper airways collapse (American Academy of Sleep Medicine 2005, Lopez-Jimenez et al. 2008). As the result of coexisting OSA with Central Sleep Apnea there are also mixed apneas (MAs) observed in OSA patients, starting typically as central apneas (CAs) and finishing as obstructive apneas (OAs) (De Backer 1995, Iber et al. 2007). Previous studies estimate that $8.8 \%-46.5 \%$ of men and $3.7 \%-30.5 \%$ of women has an Apnea-Hypopnea Index (AHI, i.e. number of apnoeas and hypopnoeas per hour of sleep) of at least 5 (Young et al. 1993, Ip et al. 2001, 2004, Tufik et al. 2010).

It is well known that higher body mass index (BMI), sex (male), advanced age and upper airway pathologies are risk factors of OSA and that supine body position worsen OSA (Leiter 1996, Oksenberg et al. 2000, Tufik et al. 2010). It is also thought that OSA is more severe in rapid eye movement (REM) sleep than in non-REM (NREM) sleep but there are some uncertainties. Although it is generally believed that mean duration of OA is longer in REM sleep (REMs) than NREM sleep (NREMs) (Sullivan and Issa 1980, Findley et al. 1985, Sériès et al. 1990, Siddiqui et al. 2006), there is no consensus about minimum $\mathrm{SaO}_{2}$. Muraki et al. (2008) found that minimum $\mathrm{SaO}_{2}$ in the Japanese population is more common in REMs than NREMs, but 
others did not find significant differences (Loadsman and Wilcox 2000, Siddiqui et al. 2006). There is especially conflicting evidence about AHI. Several studies found no difference in AHI between both sleep stages (Loadsman and Wilcox 2000, Siddiqui et al. 2006, Muraki et al. 2008). Punjabi et al. (2002) had two groups in their study (1821 and 584 subjects, with and without Multiple Sleep Latency Test respectively): the first had higher average AHI in REMs than NREMs, the second vice versa, without statistical significance. It is, however, possible that body position is a confounding factor. According to Cartwright et al. (1991), REMs is associated more with side sleeping compared to NREMs. The main aim of this study was to compare the AHI in REM and NREM sleep in both supine and lateral body position.

\section{Methods}

A retrospective chart review was performed on 422 consecutive patients (344 males and 78 females) who underwent an overnight polysomnography from March 2009 to June 2012. Polysomnography included three-channel electroencephalogram, twochannel electrooculogram, electrocardiogram, submental and leg electromyogram, thoracic and abdominal inductance plethysmography, nasal cannula, pulse oximeter, body position sensor (capable to determine 8 different body positions: supine, prone, right-hip, lefthip and 4 boundary positions), snore microphone and infrared camera (Alice3 Diagnostic Sleep System, Respironics). Records were scored manually according to the standard criteria (Iber et al. 2007) using Alice5 software. For scoring hypopneas, alternative (not recommended) criteria were used (Iber et al. 2007). Patients with total sleep time duration under $200 \mathrm{~min}$ ( 7 males and 3 females), those with a higher amount of CAs than OAs (41 males and 12 females) as well as those with REMs duration under $20 \mathrm{~min}$ (51 males and 10 females) were excluded. One man with Amyotrophic lateral sclerosis was also excluded. No minimal criteria for whole-night AHI was used, because some patients that have higher AHI in REM sleep (AHI-REMs) than NREM sleep (AHI-NREMs) would be rejected, and vice versa (e.g. if minimal criteria would be whole-night $\mathrm{AHI} \geq 5 / \mathrm{h}$, a patient with AHI-REMs $2 / \mathrm{h}$ and AHI-NREMs $10 / \mathrm{h}$ would be included, but patient with AHI-REMs $10 / \mathrm{h}$ and AHI-NREMs $2 / \mathrm{h}$ would be excluded - due to different duration of REM and NREM sleep). Only patients with whole night $\mathrm{AHI}=0$ ( 2 women and 1 man) were rejected, which means exactly the criterion: $\mathrm{AHI}>0$. The rest of the patients were eligible for the study, however not for all statistics. Values of mean durations of OA (or MA) equal to 0 were not used in the analysis. In cases when we compared AHI in REM and NREM sleep in supine or lateral (data from right- and left- hip) body position, only AHI values calculated from a 20 min minimum record were accepted (i.e. some patients were completely refused here, some were used for statistics in one position, some in both). Each value in the study is written as a mean \pm SD. Wilcoxon signed ranks test was used for statistical analysis, unless otherwise noted. $\mathrm{P}<0.05$ was considered significant. All statistics were made using SPSS statistics 17.

\section{Results}

Two hundred and forty-three men and 51 women were eligible for the study. The mean age was $48.3 \pm 12.5$ years, BMI 31.1 \pm 4.8 , and Epworth sleepiness scale (ESS) $9.0 \pm 4.9$ in men, and the average age $51.3 \pm 9.3$ years, BMI $32.0 \pm 6.3$ and ESS 9.0 \pm 4.9 in women. In men, NREMs lasted for $339.1 \pm 57.7 \mathrm{~min}$ and REMs for $61.1 \pm 30.2 \mathrm{~min}$ that means ratio $5.55 / 1$. In women, NREMs lasted $341.0 \pm 58.0 \mathrm{~min}$ and REMs $64.5 \pm 29.6 \mathrm{~min}$ that means ratio 5.28/1. Longer mean duration of $\mathrm{OA}$ and lower mean $\mathrm{O}_{2}$ saturation $\left(\mathrm{SaO}_{2}\right)$ in REMs than NREMs were found in both sexes. Mean duration of MA was also longer in REMs in men (Table 1). Whole duration of apneas and hypopneas in \% of sleep was higher in REMs than NREMs in both sexes. Women had higher AHI-REMs than AHI-NREMs $(\mathrm{P}<0.01)$, men, however, were not significantly different. Similar results were found for Oxygen Desaturation Index (ODI), i.e. number of $3 \%$ desaturations per hour of sleep (Table 1 ).

Previous studies usually, except Punjabi et al. (2002), used some minimal criteria for whole-night AHI $(<5 / \mathrm{h}$ or $<10 / \mathrm{h})$ (Loadsman and Wilcox 2000, Siddiqui et al. 2006, Muraki et al. 2008). If minimal whole-night AHI $(<5 / \mathrm{h}$ or $<10 / \mathrm{h})$ criteria were used, there would be even worse significance (Table 1).

A positive correlation was found between mean duration of OA and AHI both in REMs (Pearson =0.32) and NREMs (Pearson $=0.44$ ) (only men with $1 \mathrm{OA}$ at least in both REM and NREM sleep were used, 186 men), however a negative correlation was found between the same variables both in REMs (Pearson = $-0.35,58$ men) and NREMs (Pearson $=-0.16,52$ men) in subgroup with $A H I \geq 60 /$ h (Fig. 1). 


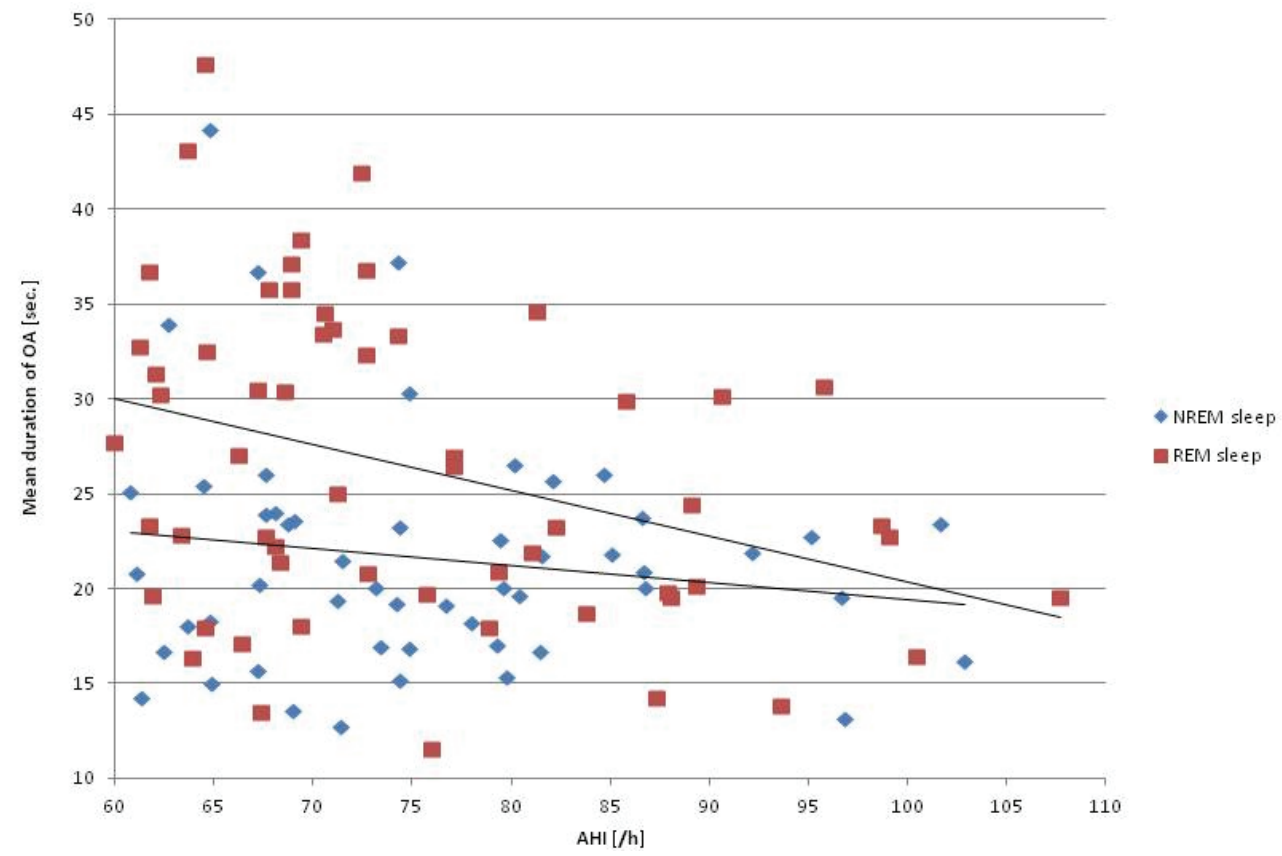

Fig. 1. Connection between mean duration of $\mathrm{OA}$ and $\mathrm{AHI} \geq 60 / \mathrm{h}$ both in REM and NREM sleep (results are irrespective of body position).

Table 1. OSA parameters in REM and NREM sleep (irrespective of body position).

\begin{tabular}{lllllllll}
\hline & \multicolumn{9}{c}{$\mathbf{M}$} & \multicolumn{3}{c}{ W } \\
\cline { 2 - 8 } & $\mathbf{n}$ & REM sleep & NREM sleep & $\mathbf{P}$ & $\mathbf{n}$ & REM sleep & NREM sleep & P \\
\hline Mean $\mathrm{SaO}_{2}$ & 243 & $91.27 \pm 4.72$ & $92.03 \pm 2.99$ & $<0.001$ & 51 & $92.35 \pm 3.33$ & $93.12 \pm 2.26$ & $=0.001$ \\
Mean dur.OA & 186 & $21.84 \pm 9.88$ & $18.22 \pm 5.34$ & $<0.001$ & 29 & $18.12 \pm 7.67$ & $15.70 \pm 4.87$ & $<0.05$ \\
Mean dur.MA & 92 & $28.64 \pm 11.15$ & $23.50 \pm 7.36$ & $<0.001$ & 8 & & & \\
AH\%-sleep & 243 & $22.54 \pm 22.79$ & $17.95 \pm 18.72$ & $<0.001$ & 51 & $16.82 \pm 19.50$ & $10.31 \pm 15.56$ & $<0.001$ \\
ODI & 243 & $34.85 \pm 27.50$ & $32.54 \pm 27.96$ & $=0.08$ & 51 & $34.08 \pm 30.95$ & $23.77 \pm 28.20$ & $=0.002$ \\
AHI & 243 & $33.60 \pm 28.68$ & $30.92 \pm 28.19$ & $=0.09$ & 51 & $30.01 \pm 30.64$ & $20.41 \pm 28.89$ & $=0.003$ \\
AHI* & 200 & $39.87 \pm 27.79$ & $37.20 \pm 27.25$ & $=0.22$ & 33 & $44.69 \pm 28.78$ & $30.82 \pm 31.40$ & $=0.003$ \\
AHI** & 175 & $43.76 \pm 27.17$ & $41.55 \pm 26.38$ & $=0.40$ & 27 & $50.03 \pm 28.69$ & $36.52 \pm 32.06$ & $=0.015$ \\
\hline
\end{tabular}

$\mathrm{M}$ - men, $\mathrm{W}$ - women, $\mathrm{n}$ - number of patients (in Mean dur. OA and Mean dur. MA, patients with values equal to 0 in REM or NREM sleep were refused), Mean $\mathrm{SaO}_{2}-$ mean $\mathrm{O}_{2}$ saturation in \%, Mean dur. $\mathrm{OA}$ - mean duration of obstructive apnea in seconds, Mean dur. MA - mean duration of mixed apnea in seconds (in women we did not do statistics because of too few patients), AH \%-sleep apnoea and hypopnoea duration in \% of sleep, ODI - Oxygen Desaturation Index, AHI*- AHI of patients with whole-night AHI $\geq 5$, $\mathrm{AHI}^{* *}-\mathrm{AHI}$ of patients with whole-night $\mathrm{AHI} \geq 10$.

Men slept 1.14 times more in lateral position during REMs than NREMs $(57.6 \pm 34.8 \%$ of REMs vs. $50.6 \pm 30.5 \%$ of NREMs, $\mathrm{P}<0.001)$ and 1.42 times more in supine position during NREMs than REMs (27.1 $\pm 28.4 \%$ of NREMs vs. $19.1 \pm 28.7 \%$ of REMs, $\mathrm{P}<0.001$ ). Women, however, probably because of low number of subjects, did not reach statistical significance. Women slept 1.15 times more in lateral position during REMs than NREMs $(46.3 \pm 41.6 \%$ of REMs vs. $40.4 \pm 32.9 \%$ of NREMs, $\mathrm{P}>0.05$ ) and 1.17 times more in supine position during NREMs than REMs (32.5 $\pm 28.7 \%$ of NREMs vs. $27.7 \pm 34.3 \%$ of REMs, $\mathrm{P}>0.05$ ).
As mentioned, for comparison of AHI in REM and NREM sleep in specific body position, some data were refused from the study because of our $20 \mathrm{~min}$ minimum record criteria for each AHI value (Table 2). Women had higher AHI in REMs than NREMs in both supine ( $46.05 \pm 26.26$ vs. $23.91 \pm 30.96, \mathrm{P}<0.01)$ and lateral $(18.16 \pm 27.68$ vs. $11.30 \pm 21.09, \mathrm{P}<0.01)$ body position (Table 3). Men had higher AHI in REMs than NREMs in lateral body position (28.94 \pm 28.44 vs. 23.58 \pm 27.31 , $\mathrm{P}<0.01$ ), however, statistical significance was not reached in supine position (Table 3 ). 
Table 2. Groups, which were used on comparison of AHI in REM and NREM sleep in specific body position.

\begin{tabular}{lllll}
\hline & n & Age (years) & BMI & ESS \\
\hline Men $-S$ & 55 & $45.7 \pm 14.2$ & $30.7 \pm 5.4$ & $8.9 \pm 5.1$ \\
Men- $L$ & 165 & $48.7 \pm 11.8$ & $30.9 \pm 4.2$ & $9.2 \pm 4.6$ \\
Women $-S$ & 15 & $53.8 \pm 8.2$ & $35.5 \pm 5.8^{*}$ & $8.9 \pm 4.3$ \\
Women $-L$ & 28 & $50.6 \pm 8.9$ & $30.5 \pm 6.3$ & $8.6 \pm 5.4$ \\
\hline
\end{tabular}

$\mathrm{n}$ - number of patients, BMI - body mass index, ESS - Epworth sleep scale, Men-S/Men-L - male group of patients that slept both in REM and in NREM sleep on supine/lateral position at least $20 \mathrm{~min}$, Women-S/Women-L - female group of patients that slept both in REM and in NREM sleep on supine/lateral position at least $20 \mathrm{~min}$, *significant difference $(\mathrm{P}=0.047)$ with original female group of 51 subjects (used Mann-Whitney U test).

\section{Discussion}

In women, AHI and ODI were higher in REMs than NREMs and AHI was higher in REMs than NREMs in both tested positions (Table 1 and 3). In men, the same tendency was observed, however statistical significance was found only in AHI in lateral body position (Table 1 and 3). Irrespective of body position, previous studies were confirmed that women, compared to men, are more prone to have higher AHI in REMs than NREMs (Table 1) (O'Connor et al. 2000, Vagiakis et al. 2006).

Longer mean duration of OA was found in REMs compared to NREMs in both sexes in accordance with previous studies (Sullivan and Issa 1980, Findley et al. 1985, Sériès et al. 1990, Siddiqui et al. 2006, Vagiakis et al. 2006, Muraki et al. 2008). Moreover, longer mean duration of MA in REMs was found in men. The current study also shows that there is also lower mean $\mathrm{SaO}_{2}$ in REMs than NREMs in both sexes. As mentioned above, contradictions exist in minimum $\mathrm{SaO}_{2}$ (Loadsman and Wilcox 2000, Siddiqui et al. 2006, Muraki et al. 2008), however, due to the different duration of REMs and NREMs, this suggests the mean value is a better variable than minimum value. Longer whole apnea-hypopnea duration in REMs than NREMs in both sexes in current study was also found (Table 1).

For interruption of OAs, arousals are needed. It is more difficult to elicit them by hypoxemia in REMs compared to NREMs that elucidates long OAs (Sullivan and Issa 1980). During REMs, however, there is also muscular hypotonia in upper airways (Horner 1996). Therefore, theoretically, AHI should also be higher in REMs compared to NREMs, which seems to be true for women but for men only in lateral position. The question remains as to why there is a problem with significance for men in supine position.

For as much as the "men in supine position" were the most severe OSA group in the current study (Table 3), the reason seems to be interaction between duration of apneas and their incidence in severe OSA patients ("severe OSA effect") as we can see in Figure 1. In REMs, there are longer OAs than in NREMs, therefore the interaction effect is stronger there. In women, one patient (BMI 50.1, age 50 years) had the AHI 78.5/h and $112.3 / \mathrm{h}$ in supine position in REM and NREM sleep, respectively, however, duration of all apneas/hypopneas in supine position was $61.3 \%$ and $47.4 \%$ of sleep in REM and NREM sleep, respectively. For reaching the same AHI during REM sleep in supine position, she would need $87.7 \%$ sleep duration of all apneas/ hypopneas. If we would reject her from the study, there would be $\mathrm{P}=0.001$ between AHI in REM and NREM sleep in women for supine position. Generally, men are more severe OSA patients than women (Vagiakis et al. 2006, Tufik et al. 2010), which holds true in the current study. This suggests a stronger effect of interaction between AHI and apnoe/hypopnoe duration. For example, in men with AHI-NREMs $>70 / \mathrm{h}$ (33 patients)

Table 3. AHI in REM and NREM sleep in supine or lateral body position.

\begin{tabular}{lccccc}
\hline & AHI -REMs-S & AHI-REMs-L & AHI-NREMs-S & AHI-NREMs-L & P \\
\hline $\begin{array}{l}\text { Men }-S \\
\text { Men- } L\end{array}$ & $49.12 \pm 32.03$ & & $45.78 \pm 34.02$ & & $=0.50$ \\
$\begin{array}{l}\text { Women- } S \\
\text { Women- } L\end{array}$ & $46.05 \pm 26.26$ & $28.94 \pm 28.44$ & & $23.58 \pm 27.31$ & $=0.002$ \\
& & $18.16 \pm 27.68$ & $23.91 \pm 30.96$ & & $=0.005$ \\
\end{tabular}

AHI-REMs-S - AHI in REM sleep in supine position; AHI-REMs-L - AHI in REM sleep in lateral position; AHI-NREMs-S - AHI in NREM sleep in supine position; AHI-NREMs-L - AHI in NREM sleep in lateral position; Men-S, Men-L, Women-S, Women-L - explained under Table 2. 
there were $24 \%$ subjects with AHI-REMs $>$ AHI-NREMs and $61 \%$ subjects with mean duration of $\mathrm{OA}$ in REMs $>30 \mathrm{~s}$ but none with both. This also implies that if there were more severe OSA patients in our study, there would be no significance for lateral position in men or generally in women as well.

According Cartwright et al. (1991), OSA patients prefer to sleep in lateral position more in REMs than NREMs, which was confirmed in the current study as significant for males contrary to females. The current study of AHI in REM and NREM sleep took body position into account, however, for OSA patients there are also beneficial positions of head and bite (Isono et al. 2004, 2005). If men prefer them more in REMs compared to NREMs similar to lateral body position, it may be another reason, along with "severe OSA effect", why no significant difference was found in AHI between REM and NREM sleep in supine position.

REMs and NREMs are not homogenous stages (Iber et al. 2007, Ermis et al. 2010). It remains to be seen if their internal changes are the cause of the significance problem in men in supine position. It is known, for example, that the tendency to apneas is very low in deep NREMs (Ratnavadivel et al. 2009) and deep NREMs is reduced in severe OSA patients (Redline et al. 2004), i.e. probably especially in supine position. However, this reduction is pathological. For example, there is well known rebound phenomenon of deep NREMs in OSA patients during first night on continuous positive airway pressure (Brillante et al. 2012). If that is the cause, then that contributes to the conclusion that physiological REMs is more prone to appearance of apneas than physiological NREMs.

There is well known co-morbidity of OSA with metabolic syndrome, back pain and periodic limb movements in sleep (Ohayon and Roth 2002, Shiri et al. 2010, Lam et al. 2012). Speculation can be made, then, about their influences on OSA in REM or NREMs, perhaps even in different body positions. These questions, however, overreach the scope of this study.
This study included patients with AHI $>0$, not $\mathrm{AHI} \geq 5$ (i.e. to treat OSA as a "symptom", not as a "disease"). The border value of $\mathrm{AHI} \geq 5$ is general consensus due to the health effects involved, however, there is no reason to assume a different mechanism for apnea in patients with $\mathrm{AHI}<5$ compared with those with $\mathrm{AHI} \geq 5$. In addition, subjects with $\mathrm{AHI}<5$ are a group of "almost healthy patients" that generally have a low or even negative effect on statistical significance. For example, there was $\mathrm{P}<0.05$ for the comparison of mean duration of OA in REM and NREM sleep in women (Table 1), however, when we used the exclusion criterion $\mathrm{AHI} \geq 5$ it became $\mathrm{P}=0.01$ and with criterion $\mathrm{AHI} \geq 10$ it became $\mathrm{P}<0.01$. Despite that, the criterion of $\mathrm{AHI}>0$ is used in the current study because of reason mentioned previously (see Methods).

In conclusion, the female data suggest that OSA is worse in REMs than NREMs for AHI in both lateral and supine position. The male data suggest that the AHI is higher in REMs than NREMs only in lateral body position. Although the same tendency was found in men even in supine position, statistical significance was not reached there. It is believed that this is the result of the interaction of apnoea/hypopnea duration and AHI in severe OSA patients. Beneficial positions of head and bite are also possible confounding factors. Pathological change of sleep or some OSA co-morbidities may also contribute to the cause. For all other measured parameters (mean $\mathrm{O}_{2}$ saturation, mean duration of $\mathrm{OA}$ and $\mathrm{MA}$, apnea and hypopnea duration in \% of sleep, ODI), OSA was worse in REMs than in NREMs in both sexes, except ODI in men $(\mathrm{P}>0.05)$ and mean duration of MA in women (no results because of too few patients) (Table 1).

\section{Conflict of Interest}

There is no conflict of interest.

\section{Acknowledgements}

The research was supported by Slovak APVV grant 2004705 and COST action B 26.

\section{References}

AMERICAN ACADEMY OF SLEEP MEDICINE: International classification of sleep disorders. Diagnostic and coding manual (ICSD-2). $2^{\text {nd }}$ ed. Westchester, IL, 2005.

BRILLANTE R, COSSA G, LIU PY, LAKS L: Rapid eye movement and slow-wave sleep rebound after one night of continuous positive airway pressure for obstructive sleep apnoea. Respirology 17: 547-553, 2012.

CARTWRIGHT RD, DIAZ F, LLOYD S: The effects of sleep posture and sleep stage on apnea frequency. Sleep 14: 351-353, 1991. 
DE BACKER WA: Central sleep apnoea, pathogenesis and treatment: an overview and perspective. Eur Respir J 8: 1372-1383, 1995.

ERMIS U, KRAKOW K, VOSS U: Arousal thresholds during human tonic and phasic REM sleep. $J$ Sleep Res 19: 400-406, 2010.

FINDLEY LJ, WILHOIT SC, SURATT PM: Apnea duration and hypoxemia during REM sleep in patients with obstructive sleep apnea. Chest 87: 432-436, 1985.

HORNER RL: Motor control of the pharyngeal musculature and implications for the pathogenesis of obstructive sleep apnea. Sleep 19: 827-853, 1996.

IBER C, ANCOLI-ISRAEL S, CHESSON A JR, QUAN S: The AASM manual for the scoring of sleep and associated events: rules, terminology and technical specifications, Westchester, IL, American Academy of Sleep Medicine, 2007.

IP MS, LAM B, LAUDER IJ, TSANG KW, CHUNG KF, MOK YW, LAM WK: A community study of sleepdisordered breathing in middle-aged Chinese men in Hong Kong. Chest 119: 62-69, 2001.

IP MS, LAM B, TANG LC, LAUDER IJ, IP TY, LAM WK: A community study of sleep-disordered breathing in middle-aged Chinese women in Hong Kong: prevalence and gender differences. Chest 125: 127-134, 2004.

ISONO S, TANAKA A, ISHIKAWA T, TAGAITO Y, NISHINO T: Sniffing position improves pharyngeal airway patency in anesthetized patients with obstructive sleep apnea. Anesthesiology 103: 489-494, 2005.

ISONO S, TANAKA A, TAGAITO Y, ISHIKAWA T, NISHINO T: Influences of head positions and bite opening on collapsibility of the passive pharynx. J Appl Physiol 97: 339-346, 2004.

LAM JC, MAK JC, IP MS: Obesity, obstructive sleep apnoea and metabolic syndrome. Respirology 17: 223-236, 2012.

LEITER JC: Upper airway shape: Is it important in the pathogenesis of obstructive sleep apnea? Am J Respir Crit Care Med 153: 894-898, 1996.

LOADSMAN JA, WILCOX I: Is obstructive sleep apnoea a rapid eye movement-predominant phenomenon? $\mathrm{Br} J$ Anaesth 85: 354-358, 2000.

LOPEZ-JIMENEZ F, SERT KUNIYOSHI FH, GAMI A, SOMERS VK: Obstructive sleep apnea: implications for cardiac and vascular disease. Chest 133: 793-804, 2008.

MURAKI M, KITAGUCHI S, ICHIHASHI H, HARAGUCHI R, IWANAGA T, KUBO H, HIGASHIYAMA A, TOHDA Y: Apnoea-hypopnoea index during rapid eye movement and non-rapid eye movement sleep in obstructive sleep apnoea. J Int Med Res 36: 906-913, 2008.

O'CONNOR C, THORNLEY KS, HANLY PJ: Gender differences in the polysomnographic features of obstructive sleep apnea. Am J Respir Crit Care Med 161: 1465-1472, 2000.

OHAYON MM, ROTH T: Prevalence of restless legs syndrome and periodic limb movement disorder in the general population. J Psychosom Res 53: 547-554, 2002.

OKSENBERG A, KHAMAYSI I, SILVERBERG DS, TARASIUK A: Association of body position with severity of apneic events in patients with severe nonpositional obstructive sleep apnea. Chest 118: 1018-1024, 2000.

PUNJABI NM, BANDEEN-ROCHE K, MARX JJ, NEUBAUER DN, SMITH PL, SCHWARTZ AR: The association between daytime sleepiness and sleep-disordered breathing in NREM and REM sleep. Sleep 25: 307-314, 2002.

RATNAVADIVEL R, CHAU N, STADLER D, YEO A, MCEVOY RD, CATCHESIDE PG: Marked reduction in obstructive sleep apnea severity in slow wave sleep. J Clin Sleep Med 5: 519-524, 2009.

REDLINE S, KIRCHNER HL, QUAN SF, GOTTLIEB DJ, KAPUR V, NEWMAN A: The effects of age, sex, ethnicity, and sleep-disordered breathing on sleep architecture. Arch Intern Med 164: 406-418, 2004.

SÉRIÈS F, CORMIER Y, LA FORGE J: Influence of apnea type and sleep stage on nocturnal postapneic desaturation. Am Rev Respir Dis 141: 1522-1526, 1990.

SHIRI R, KARPPINEN J, LEINO-ARJAS P, SOLOVIEVA S, VIIKARI-JUNTURA E: The association between obesity and low back pain: a meta-analysis. Am J Epidemiol 171: 135-154, 2010.

SIDDIQUI F, WALTERS AS, GOLDSTEIN D, LAHEY M, DESAI H: Half of patients with obstructive sleep apnea have a higher NREM AHI than REM AHI. Sleep Med 7: 281-285, 2006.

SULLIVAN CE, ISSA FG: Pathophysiological mechanisms in obstructive sleep apnea. Sleep 3: 235-246, 1980. 
TUFIK S, SANTOS-SILVA R, TADDEI JA, BITTENCOURT LR: Obstructive sleep apnea syndrome in the Sao Paulo Epidemiologic Sleep Study. Sleep Med 11: 441-446, 2010.

VAGIAKIS E, KAPSIMALIS F, LAGOGIANNI I, PERRAKI H, MINARITZOGLOU A, ALEXANDROPOULOU K, ROUSSOS C, KRYGER M: Gender differences on polysomnographic findings in Greek subjects with obstructive sleep apnea syndrome. Sleep Med 7: 424-430, 2006.

YOUNG T, PALTA M, DEMPSEY J, SKATRUD J, WEBER S, BADR S: The occurrence of sleep-disordered breathing among middle-aged adults. $N$ Engl J Med 328: 1230-1235, 1993. 